\title{
ISOLATION AND IDENTIFICATION OF THE MICROORGANISMS MOST PREVALENT IN EXTERNAL EYE INFECTIONS AS SEEN IN AN EYE CLINIC IN OWERRI
}

\author{
BY \\ ESENWAH, E. \\ MERCY EYE CLINIC, \\ 27 WETHERAL ROAD OWERRI \\ IMO STATE, NIGERIA \\ Email: esenwahemma_eye@yahoo.com
}

\begin{abstract}
Infections of the external eye account for a significant percentage of ocular inflammations, some of which lead to visual losses as result of corneal involvement. This study purely isolated and identified the microorganisms most prevalent in external eye infections in Owerri urban (as seen Mercy Eye clinic). With the aid of sterile swab sticks, specimens were collected from the lid margins, conjunctiva and corneal surfaces, as the case may be, from infected eyes and streaked immediately on blood and MacConkey plates for culture and analysis. The laboratory results revealed staphylococcus species $23.8 \%$, Escherichia coli, $15.5 \%$ and admixture of both microorganisms, $60.7 \%$.
\end{abstract}

KEYWORDS: External eye infection, Staphylococcus aureus, Escherichia coli, MacConkey agar

\section{INTRODUCTION}

External eye infections account for a significant percentage of the various ocular problems presenting in eye clinics on a daily basis. With one or two appropriate medication prescribed, by the doctor or in some other cases, self-prescribed, the infections clear.

However, during the period March-April, 2004, Owerri witnessed a higher than normal incidence of external eye infection, hence this study.

\section{MATERIALS AND METHODS}

A total of 168 patients, 67 male and 101 females, whose ages ranged from $1 \mathrm{yr}-60$ years, that presented at Mercy Eye clinic, Owerri, over a period of 4 weeks with red eye constituted the sample population.

The instruments of study were direct clinical examination and laboratory analysis. The materials used included pen-torch, ophthalmoscope, slit lamp, sterile swab sticks, basic glassware, salts and solvents. While all desirable instruments were sterilized, the glassware and media were autoclaved at $121^{\circ} \mathrm{C}$ for about 15 mins $^{1}$.

Without prejudice to routine optometric examination, specimens were collected from infected lid margins, conjunctiva and corneal surfaces with sterile swab sticks. Topical anesthetic was not necessary since it was not needed for patient comfort. Besides, it could inhibit bacterial growth if incorporated into the specimen ${ }^{2}$. The swab sticks were streaked immediately on both blood and MacConkey plates for culture. To ensure purity, each discrete colony was subculture twice.

\section{Identification of microorganism/ laboratory analysis \\ Both morphological and biochemical test for microorganism identifications were carried out.}

\section{a. Morphological Test}

Gram Staining: This identifies and differentiates gram-positive from gram-negative bacteria ${ }^{3}$. With the aid of a sterile swab stick, each discrete colony was collected and smeared on a slide with a drop of distilled water. The slid was air-dried and heat fixed over a flame.

Primary staining was achieved by using crystal violet for $1 \mathrm{~min}$, washing this off with distilled water; Gram's iodine solution was added and allowed to stand for about 30seconds before washing off. The resultant smear was decolorized by treating it with $95 \%$ ethyl alcohol (manufactured by New Health way Ltd; Lagos) for about 30 seconds and quickly rinsed with distilled water. 
Secondary staining was achieved using Safranin for 30seconds. The slide was rinsed with distilled water and blotted dry. The distribution of the stained organisms was observed in the slides with a 40X objective and an oil immersion objective. Purple colour indicated gram-positive organism while pink colour indicated gramnegative organism ${ }^{2,4}$

\section{b. Biochemical Test}

Catalase Test: Catalase acts as a catalyst in the breakdown of amino acid and hydrogen peroxide to oxygen and water.

$$
2 \mathrm{H}_{2} \mathrm{O}_{2} \Rightarrow 2 \mathrm{H}_{2 \mathrm{O}}+\mathrm{O}_{2}
$$

Using a sterile swab stick a small amount of the isolate is collected and placed on a few drops of $3 \%$ hydrogen peroxide on a clean sterile slide. The emergence of gas bubbles (effervescence) indicates the presence of staphylococcus species, while its absence indicates the presence of streptococcus species 5 .

Indole Test: This test is essential for the identification of enterobacteria such as Escherichia Coli (E Coli). Peptone water cultures already dispensed in test tubes were inoculated with the test organism. These were incubated for about 24$48 \mathrm{hrs}$ at $35-37^{\circ} \mathrm{C} .0 .5 \mathrm{ml}$ Kovac's reagent was then added to each test-tube, shaking gently.

Red colour band layer at the medium surface indicates positive result, while no red surface layer indicates negative $\mathrm{e}^{5}$.

\section{RESULTS}

As mentioned earlier, a total of 168 patients, 67 males and 101 females, constituted the study population. They all had one thing in common, red eyes-some of which were characterized and/or not characterized by pain, photophobia, tearing and pussy/mucous discharges. The data obtained was analyzed as seen in the tables below.

Conjunctivitis accounted for 98 or $58.3 \%$, corneal ulcer 28 or $16.7 \%$, keratitis 24 or $14.3 \%$ and stye 18 or $10.7 \%$ (table 1). Moderate growth of staphylococcus species alone accounted for 40 or $23.8 \%$ of the infections while moderate growth of E. coli accounted for 26 or $15.5 \%$. Insignificant growth of mixed infections of both staphylococcus and E. coli species accounted for 102 or $60.7 \%$ of the infections (table 2).

\section{DISCUSSION}

Table 2 implicates staphylococcus species as the most prevalent microorganisms responsible for these external eye infections. It accounted for $23.8 \%$ of the infections while E. coli accounted for $15.5 \%$. A mixture of both microorganisms accounted for $60.7 \%$

The normal microflora of the eye, which resembles that of the skin primarily, consists of staphylococci, coryneform bacteria and some other anaerobes ${ }^{6}$. But Fahmy et $\mathrm{al}^{7}$ demonstrated that cultures of the normal eye are frequently sterile though staphylococcus aureus may be seen occasionally but in very small number.

Therefore, increased number or significant growth of staphylococcus may suggest manifest inflammation in the eye. This assertion was proved by Thygeson ${ }^{1}$ when he reported that there was a clear correlation between clinical infection and the presence of ñnumerous coloniesò or ñconfluent growthò on culture plates. This research finding was also in line with Wilson's ${ }^{9}$ work when he reported that a ñsignificant growthò of staphylococcus or a ñconfluent growthò of staphylococcus epidermidis was compatible with persistent chronic conjunctivitis and blepharoconjunctivitis.

E. coli, on the other hands, accounted for $15.5 \%$ of the external eye infection. It is also found as part of the normal flora of the intestinal tract of humans and animals, in the soil and as plant pathogens. E. coli had been reported to be responsible for certain ocular inflammations such as endophthalmitis, keratitis, conjunctivitis, blepharitis, orbital cellulitis and dacryocystitis .

It should be noted that the period March to April, when most of these infections occurred corresponded to the beginning of the farming season in Imo State which is usually characterized by bush clearing, soil preparation and the use of improvised cheap organic fertilizers such as human and animal wastes for planting. Thus, infection is easily spread through scratches with the fingernails and rubbing of the eye with infected hands.

Another notable significant observation in this laboratory analysis is the large number of admixture of insignificant growth of staphylococcus and E. coli species. This group accounted for $60.7 \%$ a review of the case histories of the patients who fell into this category revealed 
the preponderance abusive use of self-prescribed medications - both orthodox and non-orthodox.

Among the largely abused orthodox eye drops were chloramphenicol and betametasone/ Neomycin and ampicillin capsules. On the nonorthodox side, cow urine, dry gin, sugar solutions and human breast milk were applied and in some cases simultaneously with some orthodox medication. These types of abuses may have masked the growth of these microorganisms, thus contributing to the high percentage $(60.7 \%)$ of the insignificant growth of the admixture of staphylococcus and E. Coli species ${ }^{4}$. Nevertheless, the fact remains that only staphylococcus and E. Coli species recorded growth, even if insignificant.

This study has revealed that Staphylococcus and E. Coli microorganisms are the most prevalent microorganisms responsible for most external eye infections in Owerri. These two microorganisms are known to multiply very rapidly and are spread through personal contacts. Consequently, the eradication of these diseases lie in improving the socio-economic living conditions of Nigerians.

TABLE 1: CLASSIFICATION OF EYE INFECTION OBSERVED.

\begin{tabular}{|l|c|c|}
\hline Eye infections & Freq. of occurrence & \% frequency \\
\hline Conjunctivitis (of various types) & 98 & 58.3 \\
\hline Corneal ulcer & 28 & 16.7 \\
\hline Keratitis & 24 & 14.3 \\
\hline Style & 18 & 10.7 \\
\hline Total & 168 & 100 \\
\hline
\end{tabular}

TABLE 2: RESULT OF THE LABORATORY MICROBIAL ANALYSIS

\begin{tabular}{|l|c|c|}
\hline Microorganisms & Freq. of occurrence & \% frequency \\
\hline Staph species & 40 & 23.8 \\
\hline E. coli & 26 & 15.5 \\
\hline $\begin{array}{l}\text { Mixed infection } \\
(\text { Staph/ E. coli) }\end{array}$ & 102 & 60.7 \\
\hline Total & 168 & 100 \\
\hline
\end{tabular}

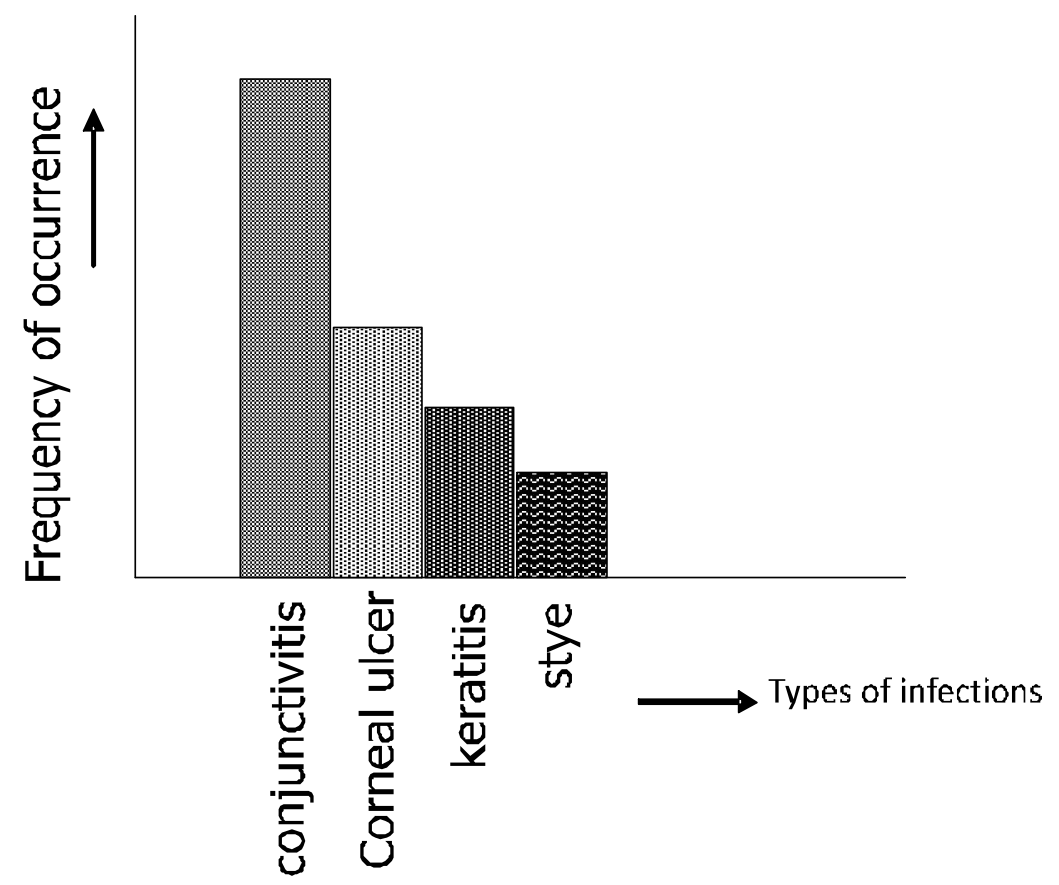

FIG.1: EXTERNAL OCULAR DISEASES OBSERVED 


\section{R E F E R E N C E S}

1. Thygeson, P. (1969): Complications of Staphylococci Blepharitis. Am. J. Ophthalmol. 68: 446

2. Briuser, J. H. and Burd, E .M. (1996): Principles of Diagnostic Ocular Microbiology. Infections of the Eye. $2^{\text {nd }}$ Edn. Little Brown Company, Boston, pp 69-77.

3. Kanski, J. J. (1997): Laboratory Investigationï Clinical Ophthalmology. $3^{\text {rd }}$ Edn. Butter and Tanner Ltd, Frome and London, pp 24.

4. Ogbulie, J. N; Uwaezuoke, J. C. and Ogiechor S. I. (1998): Introductory Microbiology Practical. Springfield Publishers, Owerri, pp 25- 57.

5. Cheesbrough M. (2000): Biochemical tests to identify bacteria. Low priced edition. District
Laboratory Practice in Tropical countries part

2. Cambridge University Press, U. K, pp 62- 72

6. Locatcher-Khorazo, D. and Seegal, B. C. (1972): The Bacterial Flora of the Healthy Eye İ Microbiology of the Eye. $1^{\text {st }}$ Edn. St. Louis, Mosby, pp 13-23.

7. Fahmy, J. A., Moller, S. and Bentzon, M. W. (1974): Bacterial Flora of the Normal conjunction. Acta Ophthalmol, 52:786.

8. Briuser, J. H. (1996): Ocular Bacteriology. Infections of the Eye. $2^{\text {nd }}$ Edn. Little Brown and Company, Boston, pp 137.

9. Wilson, L. A. (1979): Bacterial conjunctivitis. External Diseases of the Eye. L. A. Wilson Edition. Hagerstown, Md., Harper and Row, pp 31-46.. 